\title{
Effect of community integrated management of childhood illness on mothers' healthcare-seeking behaviour and home management of childhood illness in Ile-Ife, South-West Nigeria: A household survey
}

\author{
O A Ogundele, ${ }^{1} \mathrm{MB} \mathrm{ChB}, \mathrm{MPH}, \mathrm{FWACP} ; \mathrm{T}$ Ogundele, ${ }^{2} \mathrm{MB} \mathrm{ChB}, \mathrm{MPH}$; o s Olajide, ${ }^{1} \mathrm{MB}$ ChB, MPH, FWACP \\ O I Agunbiade, ${ }^{3} \mathrm{BNSc}$ \\ Department of Community Health, Obafemi Awolowo University Teaching Hospital Complex, Ile-Ife, Osun State, Nigeria \\ ${ }^{2}$ Department of Paediatrics, Obafemi Awolowo University Teaching Hospital Complex, Ile-Ife, Osun State, Nigeria \\ ${ }^{3}$ Intensive Care Unit, Obafemi Awolowo University Teaching Hospital Complex, Ile-Ife, Osun State, Nigeria
}

Corresponding author: O A Ogundele (femiaoo@yahoo.com)

\begin{abstract}
Background. Care-seeking interventions, as part of community integrated management of childhood illness (CIMCI), have the potential to substantially reduce child mortality in countries where common childhood illnesses are a major problem. Prompt and appropriate careseeking practices are important to avoid many deaths attributed to delays in or not seeking care, particularly in developing countries such as Nigeria.

Objective. To assess the effect of community-level intervention on mothers' care-seeking behaviour for common childhood illnesses and related influencing factors.

Methods. The study had a comparative cross-sectional design and was conducted in two local government areas (LGAs) of Osun State, South-West Nigeria. A total of 722 mothers of index children aged $<5$ years were selected through a multistage cluster sampling technique. Data were collected and analysed using SPSS version 16.0. Descriptive, bivariate and multivariate analyses were performed.

Results. Care-seeking for children who reported illness was higher in the CIMCI-implementing LGA (90.2\%) compared with $74.8 \%$ in the non-implementing LGA $(p=0.002)$. Care was sought within the first 48 hours of perceived onset of illness for $83.2 \%$ and $57.9 \%$ of sick children in the CIMCI-implementing and non-implementing LGAs, respectively. Residing in a CIMCI-implementing area (odds ratio (OR) 2.54, 95\% confidence interval (CI) 1.24 - 5.45) and maternal education level (OR 1.50, 95\% CI 1.06 - 3.03) were identified as predictors of healthcare-seeking practices among mothers.

Conclusion. The study concluded that a high level of care-seeking behaviour exists where community-level intervention was operating. Therefore the CIMCI programme should be strengthened further and also scaled up to include non-implementing communities.
\end{abstract}

S Afr J Child Health 2016;10(1):16-19. DOI:10.7196/SAJCH.2016.v106i1.912

Untreated infections are a major cause of childhood mortality and morbidity in developing countries. ${ }^{[1]}$ While uncomplicated illness can be treated at home, severe illness should be treated by a health professional. Most child deaths occurring in low- and middle-income countries such as Nigeria are attributable to a handful of diseases and are avoidable through existing interventions ${ }^{[2]}$ such as the integrated management of childhood illness (IMCI) strategy developed by the World Health Organization (WHO), the United Nations Children's Fund and other technical partners. ${ }^{[3-5]}$ In Nigeria currently 3 out of 20 children die before their fifth birthday, and $70 \%$ of these deaths are due to acute respiratory infections (mostly pneumonia), diarrhoea, measles, malaria or malnutrition - and often a combination of these. ${ }^{[6,7]}$ The WHO has estimated that seeking prompt and appropriate care could reduce child deaths due to acute respiratory infections by $20 \% .{ }^{[8]}$

A high number of children die without ever being taken to a health facility, indicating that the prevalence of appropriate care-seeking is low. Even for those who are taken to a health facility, visits are often not timely enough. Appropriate care-seeking means that the need to take the child for treatment outside the home is recognised, that the care is not delayed, and that the child is taken to an appropriate health facility or provider. Interventions to improve care-seeking behaviour include health education of caregivers through training of community health workers. ${ }^{[9]}$

Community IMCI (CIMCI) is an integrated childcare approach that aims at improving household and community practices that are likely to have the greatest effect on child survival, growth and development. These key practices are growth promotion and development, disease prevention, home management, care-seeking and compliance. CIMCI has become important because most children die at home in spite of availability of health services. ${ }^{[4]}$ CIMCI was implemented in Ife Central local government area (LGA) in 2005. Community resource persons (CORPs) were trained to provide information and mobilise caregivers on child survival at household and community level. CORPs provide information on appropriate care-seeking and encourage as much as possible that caregivers adopt these practices. The CIMCI strategy has now operated for more than 6 years in communities and households to promote improved preventive and curative health behaviours.

The objective of this study was to assess the effect of community-level intervention on mothers' care-seeking behaviour for common childhood illnesses, and the factors that influenced the mothers' behaviour.

\section{Methods \\ Study sites}

The study was of a comparative cross-sectional design, and was conducted between October and December 2012 in two LGAs of Osun State in South-West Nigeria. This state has a population of about 3.4 million $^{[10]}$ people. Ife Central Local Government, the study site, implements CIMCI. Ilesa East Local Government, the comparison site, does not implement the CIMCI programme. A tertiary health facility exists in both LGAs. There are 11 primary healthcare centre 
facilities and one comprehensive healthcare centre in the 11 wards in each of the selected LGAs. The community settlement is organised into streets in both of these LGAs, which comprise both rural and urban communities.

\section{Study population and sample size}

The study population was mothers of children 0 - 59 months old, and their index children (the child selected for the study). Excluded from the study were mothers or caregivers who did not give consent or whose children were ill during the study period.

The sample size was determined using a formula for comparing independent proportions. This gave a sample size of 722 mothers or caregivers and their index children aged $<5$ years.

\section{Sampling technique}

A multistage cluster sampling technique was used to select 361 respondents each from the two study areas.

\section{Stage 1}

Ife Central LGA was purposively selected from the 30 LGAs in the state as the only LGA that implements CIMCI. Ilesa East LGA, the comparison LGA, was randomly selected from among the non-CIMCI-implementing LGAs in the state.

\section{Stage 2}

Wards 4 and 5 in Ife Central LGA were purposively selected, being the only two wards in the LGA that were implementing CIMCI, while wards 2 and 8 were randomly selected by balloting system from among the 11 wards in Ilesa East LGA.

\section{Stage 3}

The enumeration areas (EAs) of the two implementing wards (wards 4 and 5) and those of the two randomly selected wards (wards 2 and 8) were made the primary sampling units. One-fifth of the EAs in each LGA were selected using simple random selection. At each site the sample size of 361 was divided by the selected EAs to determine the number of respondents to be recruited from each EA. Ife Central had 180 EAs, from which 36 EAs were selected, while Ilesa East had 150 EAs, from which 30 EAs were selected. An average of 10 respondents were recruited from selected EAs in wards 4 and 5 in Ife Central and 12 respondents from the selected EAs in wards 2 and 8 in Ilesa East until the sample size of 361 was obtained in each LGA.

\section{Stage 4}

Household listings for streets in the EAs were done in both LGAs. One street was randomly selected from each EA by the ballot system. A household was randomly selected as the starting point in the selected street, and systematic random selection of households was carried out. Interviews began in the first eligible household, moving systematically until the targeted number of interviews had been obtained.

\section{Stage 5}

The basic sampling unit was the household, and one mother/caregiver with an eligible child was interviewed in every household that was selected. In situations where the household had more than one eligible subject, the child with a birthday nearest to the interview period was chosen.

\section{Data collection instrument}

A structured, pretested interviewer-administered questionnaire was used for data collection. The questionnaire was adapted from that previously used and validated by the WHO Nigeria. ${ }^{[1]}$ The instrument covered four key areas of household practices: growth promotion, disease prevention, home management, and care seeking. Five appropriately trained research assistants were recruited to assist in data collection. The interviewers were given an interview guide that was developed before the training.

\section{Ethical clearance}

Ethical clearance was obtained from the Ethics and Research Committee of Obafemi Awolowo University Teaching Hospitals Complex. Written informed consent was obtained from the study participants.

\section{Data analysis}

The data were analysed using SPSS version 16.0 (SPSS Inc., Chicago). Appropriate univariate, bivariate and multivariate analyses were done. Factors that were significantly associated $(p<0.05)$ with healthcare-seeking behaviour were then used in logistic regression models to estimate associations of each covariate with this behaviour. A wealth index was constructed by assessing the presence or absence of durable assets in the household.

Table 1. Sociodemographic characteristics of respondents and index child by LGA $(N=361)$

\begin{tabular}{|c|c|c|c|}
\hline Characteristics & $\begin{array}{l}\text { CIMCI- } \\
\text { implementing } \\
\text { LGA, } n(\%)\end{array}$ & $\begin{array}{l}\text { Non-CIMCI } \\
\text { LGA, } \boldsymbol{n}(\%)\end{array}$ & Statistical indices ${ }^{\star}$ \\
\hline Maternal age (years) & & & $\chi^{2}=0.355, \mathrm{df}=1, p=0.552$ \\
\hline$\leq 30$ & $178(49.3)$ & $170(47.1)$ & \\
\hline$>31$ & $183(50.7)$ & $191(52.9)$ & \\
\hline Marital status & & & $\chi^{2}=2.43, \mathrm{df}=1, p=0.119$ \\
\hline Married & 339 (93.9) & $348(96.4)$ & \\
\hline Not married & $22(6.1)$ & $13(3.6)$ & \\
\hline Maternal education status & & & $\chi^{2}=23.20, \mathrm{df}=1, p<0.001$ \\
\hline Below secondary education & $87(24.1)$ & $38(10.5)$ & \\
\hline Secondary and above & $274(75.9)$ & $323(89.5)$ & \\
\hline Maternal occupation & & & $\chi^{2}=8.400, \mathrm{df}=1, p=0.004$ \\
\hline Housewife & $18(5.0)$ & $39(10.8)$ & \\
\hline Not housewife & $343(95.0)$ & $322(89.2)$ & \\
\hline Sex & & & $\chi^{2}=1.10, \mathrm{df}=1, p=0.290$ \\
\hline Male & 209 (57.9) & $195(54.0)$ & \\
\hline Female & $152(42.1)$ & $166(46.0)$ & \\
\hline Index children age (months) & & & $\chi^{2}=24.78, \mathrm{df}=1, p<0.001$ \\
\hline$\leq 11$ & $76(21.1)$ & $37(38.0)$ & \\
\hline$>12-59$ & $285(78.9)$ & $224(62.0)$ & \\
\hline Wealth index & & & $\chi^{2}=0.894, \mathrm{df}=1, p=0.344$ \\
\hline First and second quintile & $234(64.8)$ & $246(68.1)$ & \\
\hline Third and above & $127(35.2)$ & $115(31.9)$ & \\
\hline Family size & & & $\chi^{2}=16.41, \mathrm{df}=1, p<0.001$ \\
\hline$\leq 5$ & $248(68.7)$ & $295(81.7)$ & \\
\hline$\geq 6$ & $133(31.3)$ & $66(18.3)$ & \\
\hline $\mathrm{df}=$ degrees of freedom. & & & \\
\hline
\end{tabular}


Presence was scored as 1 and absence as 0 , and the mean assets score was recategorised into five different wealth quintiles of equal proportions (lowest, second, third, fourth and highest wealth quintiles).

\section{Results}

A total of 722 households with children aged $0-59$ months were enrolled in the study (Table 1). Almost $90 \%$ of mothers in the non-implementing LGA had secondary school education and above, compared with $75.9 \%$ in the CIMCI-implementing LGA $(p<0.001)$. Only $5 \%$ of mothers in the implementing LGA and $10.8 \%$ in the non-implementing LGA were housewives. More than half $(57.9 \%$ and $54 \%$ ) of the children from the implementing areas and non-implementing areas respectively were males. About $65 \%$ of study respondents in the CIMCI-implementing LGA were in the first and second wealth quintiles, compared with $68.1 \%$ in the non-implementing LGA; this difference was not statistically significant $(p=0.344)$.

Within 2 weeks of the survey, $31 \%$ and $35.2 \%$ of index children in the CIMCI-implementing LGA and the nonimplementing LGA were reported to have been ill (Table 2). Of these children, a higher proportion of those from the CIMCIimplementing LGA $(90.2 \%)$ were taken to health facilities compared to $74.8 \%$ from the non-implementing LGA $(p=0.002)$. Fever, cough and diarrhoea were common symptoms in both LGAs, but were more frequent in the non-implementing LGA (88.4\% in the implementing and $99.2 \%$ in the non-implementing LGA), this difference being statistically significant $(p<0.001)$. Of the total treated episodes of illnesses, care was sought more frequently within the first 2 days (48 hours) of perceived onset of illness in the implementing than in the non-implementing LGA $(83.2 \%$ and $57.9 \%$ of sick children, respectively; $p<0.001$ ). In the rest of the cases - $16.8 \%$ in the implementing LGA and $42.1 \%$ in the nonimplementing LGA - care was sought from the third day onward.

As regards home treatment (Fig. 1), 25\% of caregivers in the implementing LGA did not give any form of initial treatment before seeking care, compared with $8.7 \%$ in the non-implementing LGA. About $35.5 \%$ of caregivers in the non-implementing LGA gave paracetamol as an initial treatment, while tepid sponging was a very common practice in the implementing LGA $(18.8 \%)$, compared with $4.7 \%$ in the nonimplementing LGA.

At the bivariate analyses level, residing in CIMCI-implementing LGA $(p<0.001)$ and mothers' education level $(p=0.001)$ were significantly associated with care-seeking,

Table 2. Mothers' healthcare-seeking practices for children with reported illness 2 weeks prior to study, by LGA $(N=361)$

\begin{tabular}{|c|c|c|c|}
\hline & $\begin{array}{l}\text { CIMCI- } \\
\text { implementing } \\
\text { LGA, } n(\%)\end{array}$ & $\begin{array}{l}\text { Non-CIMCI } \\
\text { LGA, } n(\%)\end{array}$ & Statistical indices \\
\hline $\begin{array}{l}\text { Index child sick } 2 \text { weeks prior } \\
\text { to survey }\end{array}$ & & & $\chi^{2}=1.41, \mathrm{df}=1, p=0.236$ \\
\hline Yes & $112(31.0)$ & $127(35.2)$ & \\
\hline No & $249(69.0)$ & $234(64.8)$ & \\
\hline Total & $361(100)$ & $361(100)$ & \\
\hline Symptoms/signs of illness ${ }^{*}$ & & & $\chi^{2}=12.63, \mathrm{df}=1, p<0.001$ \\
\hline Fever, cough and diarrhoea & $99(88.4)$ & $126(99.2)$ & \\
\hline Others & $13(11.6)$ & $1(0.8)$ & \\
\hline Total & $112(100)$ & $127(100)$ & \\
\hline Children taken to health facility & & & $\chi^{2}=9.49, \mathrm{df}=1, p=0.002$ \\
\hline Yes & $101(90.2)$ & $95(74.8)$ & \\
\hline No & $11(9.8)$ & $32(25.2)$ & \\
\hline Total & $112(100)$ & $127(100)$ & \\
\hline $\begin{array}{l}\text { Time to care-seeking after onset } \\
\text { of illness }\end{array}$ & & & $\chi^{2}=15.16, \mathrm{df}=1, p<0.001$ \\
\hline 1st and 2nd day & $84(83.2)$ & $55(57.9)$ & \\
\hline 3rd day and after & $17(16.8)$ & $40(42.1)$ & \\
\hline Total & $101(100)$ & $95(100)$ & \\
\hline
\end{tabular}

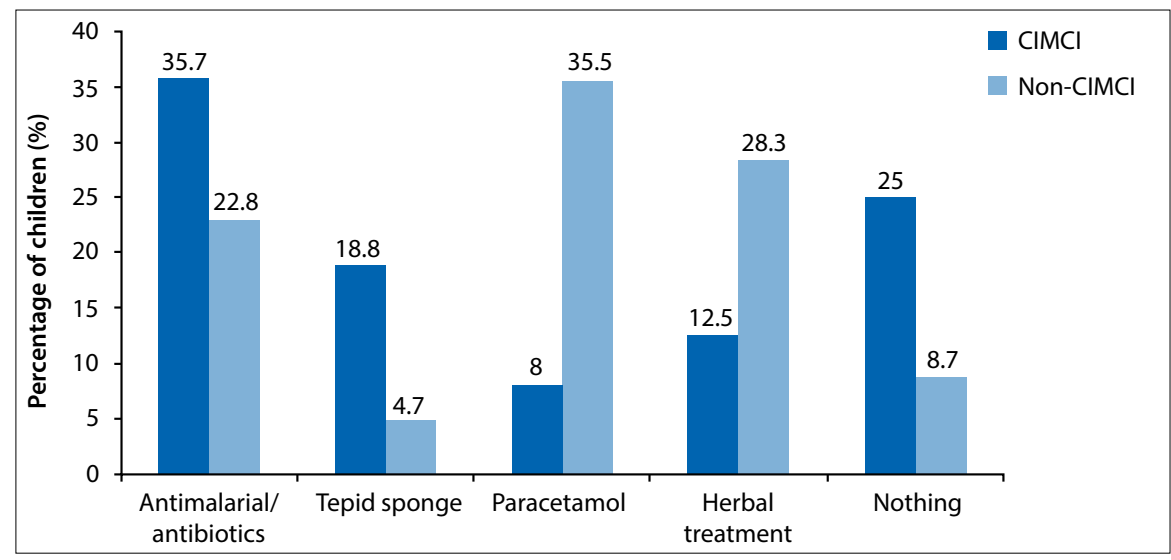

Fig. 1. Home treatment of children who reported illness 2 weeks prior to study.

while age of mothers, age of the child, family size, marital status, occupation and wealth index were not statistically significant.

A multivariate logistic regression analysis was done to determine which selected sociodemographic characteristics were associated with healthcare-seeking behaviour among mothers (Table 3 ). The result revealed that mothers who reside in the CIMCIimplementing area (odds ratio (OR) 2.54, 95\% confidence interval (CI) $1.24-5.45)$ and those who had secondary education and above (OR 1.50, 95\% CI 1.06 - 3.03) were more likely to seek care from the health facilities than the others.

\section{Discussion}

Prompt and appropriate care-seeking practice is very important to avoid many deaths attributed to delays and not seeking care, particularly in developing countries. In this study care was sought from health facilities for nine in ten sick children in the CIMCI-implementing LGAs compared with seven in ten in the non-implementing LGAs; the difference was statistically significant. Adegboyega et al. ${ }^{[12]}$ in a study in Lagos, Nigeria, reported the prevalence of care-seeking as less than that observed in this study. The difference observed in this study may therefore not be unconnected 
Table 3. Factors associated with healthcare-seeking behaviours of mothers for common childhood illnesses in Ile Ife, Nigeria $(N=722)$

\begin{tabular}{|c|c|c|}
\hline Variable & OR (95\% CI) & $p$-value \\
\hline $\begin{array}{l}\text { Maternal age }(\text { Ref }=\leq 30 \mathrm{yr}) \\
\geq 31 \mathrm{yr}\end{array}$ & $0.18(0.12-1.28)$ & 0.655 \\
\hline $\begin{array}{l}\text { Mother's education ( } \mathrm{Ref}=<\text { secondary }) \\
\geq \text { Secondary }\end{array}$ & $1.50(1.06-3.03)$ & $0.001^{*}$ \\
\hline $\begin{array}{l}\text { Marital status }(\mathrm{Ref}=\text { not married }) \\
\text { Married }\end{array}$ & $1.12(0.35-4.42)$ & 0.130 \\
\hline $\begin{array}{l}\text { Family size }(\operatorname{Ref}=n \geq 6) \\
\leq 5\end{array}$ & $1.50(0.69-3.12)$ & 0.143 \\
\hline $\begin{array}{l}\text { Occupation }(\text { Ref }=\text { housewives }) \\
\text { Not housewives }\end{array}$ & $0.52(0.33-1.47)$ & 0.780 \\
\hline $\begin{array}{l}\text { Residence }(\text { Ref }=\text { non-CIMCI }) \\
\text { CIMCI }\end{array}$ & $2.54(1.24-5.45)$ & $0.001^{\star}$ \\
\hline $\begin{array}{l}\text { Wealth index (Ref = 1st and 2nd) } \\
\text { 3rd quintile and above }\end{array}$ & $0.46(0.30-1.30)$ & 0.216 \\
\hline $\begin{array}{l}\text { Age of the child (Ref }=<11 \text { months) } \\
>12 \text { months }\end{array}$ & $0.86(0.51-1.45)$ & 0.677 \\
\hline $\begin{array}{l}\text { Ref }=\text { reference. } \\
{ }^{*} \text { Significant at the level of } p<0.05\end{array}$ & & \\
\hline
\end{tabular}

to the effect of CIMCI implementation in the study area. Here CORPs were trained at the inception of the programme to provide information on appropriate care seeking to caregivers at household and community level, and to motivate them in adopting the practices as much as possible (findings from focus group discussion not reported here). Poor care-seeking practices have, however, been reported from Ethiopia and other developing countries, ${ }^{[13,14]}$ unlike in this study, and this could be due to differences in access to health facilities, educational backgrounds, cultural factors and socioeconomic status.

For most mothers and caregivers in the CIMCI-implementing LGA in this study, care-seeking for childhood illness begins within the initial 48 hours, compared with the non-implementing LGA, where four in ten mothers and caregivers seek care on the third day or later. This is in keeping with findings by Tinuade et al., ${ }^{[15]}$ who observed that care-seeking is often delayed beyond 24 hours, and that most mothers sought initial care at home. Possible reasons for delay could be to try home care including traditional treatment, a lack of money, inadequate access to health facilities and poor illness perception.

Home treatment patterns also differed significantly between CIMCI-implementing and non-implementing communities; $\sim 19 \%$ of mothers tepid sponge for fever in the implementing LGA, compared with $\sim 5 \%$ in the non-implementing LGA. The preference for tepid sponging in the CIMCI-implementing LGA is to ensure that the fever does not get too high before mothers seek care, to make sure that the pattern of the fever is not marred before presentation, and to discourage inappropriate drug use. Most mothers gave some form of treatment, ranging from paracetamol, antimalarials and antibiotics, which was consistent with findings in other studies. $^{[14,16]}$

In this study the mother's level of education and residence in a CIMCI-implementing area were predictors of care-seeking. This is in keeping with existing studies ${ }^{[13]}$ that have shown the same, as well as other factors such as economic status, mothers' age, ethnicity and distance from the health facility.

\section{Study limitations}

A limitation of this study was the crosssectional study design, which measured the exposure and outcome at the same time, and cannot measure the cause-and-effect relationship. There was also no measure of an adverse effect on the child of delay in seeking healthcare. Another issue is that respondents may not reveal their actual practice for fear of unknown action. This was, however, minimised by interviewers first gaining the confidence of the respondents.

\section{Conclusion}

The findings of this study showed the positive effect of community-level intervention in improving healthcare-seeking behaviour. The CIMCI programme should therefore be strengthened and scaled-up to nonimplementing communities.

\section{References}

1. Aguilar AM, Alvarado R, Cordero D, et al Mortality Survey in Bolivia: The Final Report. Investigating and Identifying the Causes of Death for Children Under Five. Arlington, USA: Basic Support for Institutionalizing Child Survival (BASICS) Project, 1998

2. World Health Organization. World Health Report Geneva, Switzerland: World Health Organization, 2004.

3. United Nations Children's Fund. A Working Paper on Home and Community Health Care to Enhance Child Survival, Growth and Development. New York: UNICEF, 1999.

4. World Health Organization. Improving family and community practices. A component of the IMCI strategy. Bull WHO 1998;73(15):119-128.

5. World Health Organization/Child and Adolescent Health. Community and Household Moving Forward Programme - Report. Geneva: World Health Organization, 2000.

6. National Population Commission. Nigeria Demographic and Health Survey 2008. Calverton, USA: ICF Macro, 2009.

7. Policy Project Nigeria. Child Survival in Nigeria: Situation, Response, and Prospects. October 2002 http://www.policyproject.com/pubs/countryreports/ nig_csrevised.pdf (accessed 28 January 2016).

8. Victora C, Jennifer B, Olivier F, Roeland M. Reducing deaths from diarrhoea through oral rehydration therapy. Bull WHO 2000;1(78):10

9. Hill Z. Recognized childhood illness and thei traditional explanation: Exploring options for careseeking interventions in the context of the IMCI strategy. Trop Med Int Health 2003;8(7):668-676. [http://dx.doi.org/10.1046/j.1365-3156.2003.01058.x]

10. Ministry of Health Osogbo. Osun State Health Facilities Inventory. Osogbo, Nigeria: Ministry of Health Osogbo, 2009:7-8.

11. United Nations Children's Fund/Federal Ministry of health. IMCI in the Hands of Families: Nigeria Country Report of Baseline Studies on Key Family and Community Practices in IMCI-implemented LGAs. Abuja, Nigeria: Federal Ministry of Health, 2005.

12. Adegboyega AA, Onayade AA, Salawu O Care-seeking behaviour of caregivers for common childhood illnesses in Lagos Island Local Government Area, Nigeria. Niger J Med 2005;14(4):461.

13. Assefa T, Belachew T, Tegegn A, Deribew A Mothers' health care seeking behavior for childhood illnesses in Derra district, Northshoa zone, Oromia regional state, Ethiopia. Ethiop J Health Sci 2008;18(3):87-94

14. Tessema F, Makonnen A, Fekadu A. Mothers health services utilization and health care seeking behavior during infant rearing: West Ethiopia Ethiop J Health Dev 2002;16(Special Issue):51-58.

15. Tinuade O, Iyabo RA, Durotoye O. Health-careseeking behaviour for childhood illnesses in a resource-poor setting. I Paediatr Child Health 2010:46(5):238-242. [http://dx.doi.org/10.1111/ j.1440-1754.2009.01677.x]

16. Olaogun AA, Adebayo AA, Ayandiran OE Olasode OA. Effects of mothers' socio-economic status on the management of febrile conditions in their under five children in a resource limited setting. BMC Int Health Hum Rights 2006;6:1 [http://dx.doi.org/ 10.1186/1472-698X-6-1] 